\title{
A balanced perspective for management of tracheal salivary gland-type carcinomas
}

\author{
Chadrick E. Denlinger, MD
}

I read with great interest the article by Wurtz and colleagues describing their experience with aortic allografts for tracheal reconstruction after resection of salivary gland-type tumors. A series of 6 patients underwent tracheal resection for adenoid cystic carcinoma (ACC) $(n=5)$ or a mucoepidermoid tumor $(\mathrm{n}=1)$. Three patients required tracheal resections measuring $5.5,9$, and $10.5 \mathrm{~cm}$. Resections in the remaining 3 patients extended from the first, second, or sixth tracheal ring to at least the level of the carina. Negative resection margins were achieved by frozen section analysis in each case. An average of 5.3 frozen sections was required, and it is unclear how much additional tracheal length was resected to achieve negative margins compared with the initial resection. In each case, the trachea was reconstructed with an aortic allograft supported with a silicone stent.

With a mean follow-up of 32 months, several significant complications were honestly described by the authors. These complications included tracheoesophageal fistulas $(n=3)$, an anastomotic dehiscence, anterior spinal cord ischemia, sternal dehiscence, acquired respiratory distress syndrome, and a single patient who required 11 tracheal stent replacements. Two patients required a tracheostomy, and the mean length of hospital stay was 46 days. At the time of article submission, 4 of 6 patients were free of disease. One patient had died of distant metastatic disease, and another patient died of massive hemoptysis.

The authors should be congratulated for their attempts to advance our ability to surgically treat central airway tumors. The described case series represents a logical step following their own previously published report of 2 cases $^{1}$ and prior large animal studies. ${ }^{2}$ However, this operation, with the numerous major complications, should be interpreted in the context of more traditional treatment strategies.

Microscopically positive margins in patients with ACC have been previously accepted and treated with adjuvant radiation in this disease characterized by extensive submucosal and perineural invasion. Maziak and associates ${ }^{3}$ reported actuarial survivals of $79 \%$ and $51 \%$ at 5 and 10 years, respectively, for patients with ACC. Fifty percent of the 32 patients had microscopic evidence of disease at the resection margins, which resulted in a slight decrease in median survival (7.5 vs 9.8 years). An additional 6 patients in this series had unresectable disease and were treated with external beam radiation, resulting in a median survival of 6.2 years. Interestingly, this series reported a 30-day mortality in 3 of 32 patients treated surgically. Two of the 3 who died during the 30-day operative period required reconstruction with a prosthetic mesh. Similarly, a large series of tracheal resections with primary anastomoses and adjuvant radiation by Grillo and Mathisen ${ }^{4}$ included 60 patients with ACC. No survival difference was noted between patients with positive surgical margins and patients undergoing complete resection.

Although achieving negative resection margins intuitively seems more acceptable than microscopic residual disease, the frequency of severe complications associated with tracheal replacement strategies may render the treatment worse than the disease. Further advancements need to be made before tracheal replacement for salivary gland tumors becomes the standard treatment.

\section{References}

1. Wurtz A, Porte H, Conti M, Desbordes J, Azorin JF, Martinod E, et al. Tracheal replacement with aortic allografts. $N$ Engl J Med. 2006;355: 1938-40.

2. Jaillard S, Holder-Espinasse M, Hubert T, Copin MC, Duterque-Coquillaud M, Wurtz A, et al. Tracheal replacement with allogenic aorta in the pig. Chest. 2006;130:1397-404.

3. Maziak DE, Todd TRJ, Keshavjee SH, Winton TL, Van Nostrand P, Pearson FG. Adenoid cystic carcinoma of the airway: thirty-two-year experience. J Thorac Cardiovasc Surg. 1996;112:1522-32.

4. Grillo HC, Mathisen DJ. Primary tracheal tumors: treatment and results. Ann Thorac Surg. 1990;49:69-77.

From the Division of Cardiothoracic Surgery, Medical University of South Carolina, Charleston, SC.

Received for publication Jan 24, 2010; accepted for publication Jan 27, 2010.

Address for reprints: Chadrick E. Denlinger, MD, 25 Courtenay Dr, Suite 7018 ,

Charleston, SC 29425 (E-mail: denlinge@musc.edu).

J Thorac Cardiovasc Surg 2010;140:394.

$0022-5223 / \$ 36.00$

Copyright $(\underset{2010}{ } 20 \mathrm{by}$ The American Association for Thoracic Surgery

doi:10.1016/j.jtcvs.2010.01.035 